\title{
It's all about location
}

Citation for published version (APA):

Shiri - Sverdlov, R. (2016). It's all about location: the bridge between lipids and inflammation. Maastricht University. https://doi.org/10.26481/spe.20161206rss

Document status and date:

Published: 06/12/2016

DOI:

10.26481/spe.20161206rss

Document Version:

Publisher's PDF, also known as Version of record

\section{Document license:}

Unspecified

\section{Please check the document version of this publication:}

- A submitted manuscript is the version of the article upon submission and before peer-review. There can be important differences between the submitted version and the official published version of record.

People interested in the research are advised to contact the author for the final version of the publication, or visit the DOI to the publisher's website.

- The final author version and the galley proof are versions of the publication after peer review.

- The final published version features the final layout of the paper including the volume, issue and page numbers.

Link to publication

\footnotetext{
General rights rights.

- You may freely distribute the URL identifying the publication in the public portal. please follow below link for the End User Agreement:

www.umlib.nl/taverne-license

Take down policy

If you believe that this document breaches copyright please contact us at:

repository@maastrichtuniversity.nl

providing details and we will investigate your claim.
}

Copyright and moral rights for the publications made accessible in the public portal are retained by the authors and/or other copyright owners and it is a condition of accessing publications that users recognise and abide by the legal requirements associated with these

- Users may download and print one copy of any publication from the public portal for the purpose of private study or research.

- You may not further distribute the material or use it for any profit-making activity or commercial gain

If the publication is distributed under the terms of Article $25 \mathrm{fa}$ of the Dutch Copyright Act, indicated by the "Taverne" license above, 


\section{Maastricht University}

Prof. dr. Ronit Shiri-Sverdlov

Faculty of Health, Medicine and Life Sciences

\section{Its all about location : the bridge between lipids and inflammation}




\section{Inaugural lecture}

Dear Prorector, colleagues, friends and family,

On the left picture you can see the beautiful beach of Tel-Aviv. This is the place, the "location" if you like, where my husband first came up with idea of relocation to the Netherlands.

In the beginning, I didn't like the idea of moving to Maastricht at all. I felt comfortable and happy just where I was, as by nature I am afraid of changes and above all, I have always been and am very close to my dear and warm family. So, leaving far away from them was absolutely out of the question for me. But after a lot of negotiation, which included soft pressure from my husband and some demands from my side, I eventually agreed to move to Maastricht. My major condition: that it will be for only two years! And so, on that summer, 15 years ago,we began packing our comfortable life in Tel Aviv, having no clue what a huge impact this decision to change location will have on our life...

Today, as my family from Israel is sitting here, I am standing once again on this same bridge that I built between my life in Tel-Aviv and my life in Maastricht. Standing here, on this special moment, I would like to share with you, how crossing this bridge influenced both my scientific career and my personal life, how it is all about location.

Apart for the obvious changes in scenery, food, weather and culture, moving to Maastricht also led to changes in my scientific interests.

In Tel Aviv, my research was focused on breast cancer and genetics. In Maastricht, in line with the interests of the late Prof Marten Hofker who offered me a position in his group, I switched topics to hyperlipidemia and liver. 
But that was the easy part. It was much more difficult for me to deal with the fact that most of Marten's research dealt with mice,...and as such it implied that I needed to make a shift from human to mouse research. And ...how can I say it gently, I am not exactly a big fan of mice. Luckily for me, I realised already back then that what really counts are the people you work with, that it is so important to be surrounded by colleagues that you like and admire.

So, shortly after I arrived in Maastricht, Marten and I collaborated with Prof Marc van Bilsen to investigate the effect of unhealthy diet on the liver. In this research, we didn't use regular mice but rather mice with high levels of lipids in their blood: so-called hyperlipidemic mice. We were interested specifically in these mice due the fact that in contrast to regular mice, the lipid profiles in the blood of the hyperlipidemic mice is similar to humans. The fact that these mice have high levels of lipids in their blood also means that just like humans, they are more susceptible to develop metabolic complications such as cardiovascular diseases. But our focus was not on cardiovascular diseases but rather on the effect of unhealthy diet on their liver. We started by performing a simple experiment: we took two groups of mice: WT mice which have normal levels of lipids in their blood and hyperlipidemic mice which have high levels of lipids in their blood. We fed the mice either an unhealthy diet, rich in fat and cholesterol, or healthy diet for a period of 3 weeks, and then we investigated the livers.

If the mice receiving a healthy diet, it didn't matter whether they had high levels of lipids in their blood or not, their liver remained healthy. Strikingly, if the mice were fed an unhealthy diet, we observed a clear difference between the two groups: In the regular mice, we observed lipid droplets in the liver. Meaning that fat accumulated in the liver in excessive amounts, thus resulting in a fatty liver. But to our surprise, in the liver of the hyperlipidmic mice, we did not only observe lipid droplets but also excessive inflammation (as indicated by the inflammatory cells that infiltrated to the liver.) So the hyperlipidemic mice demonstrated a combination between fat accumulation in the liver and inflammation. 
Why did we find this combination so exciting? Well, the phenotype that we observed in the liver of hyperlipdemic mice was identical to a disease that was discovered already in 1980. In this very first publication an "unnamed disease" back then was described as observed mainly in morbidly obese people drinking no or very little amounts of alcohol. Surprisingly, the damage in the liver of this patients was described as a damage that was till then only seen in people consuming high levels of alcohol. For this reason the disease was named "non-alcoholic steatohepatitis" or in the abbreviated form: NASH. This publication ended with the statement: "Currently, we know of no effective therapy". Back then they identified the disease but didn't have any treatment.

So, what was discovered in the two decades that passed between this publication and the time that we started to work on the hyperlipidemic mice? Amazingly and to our surprise, in more than twenty years there was little or no progress in the field of NASH... This review from 2003 (so two decades after the original publication that I showed you) put forward the question "are we smarter about NASH now"? the answer on this question was: NO. The reason for the lack of development in this field as stated in this paper was the lack of a physiological mouse model that resembles human NASH. Taking into account that it is difficult to obtain repetitive human liver biopsies due to the risks associated with this procedure, it was clear that there was a need for such a model. So after further researching the topic and the available mouse models, we concluded that our mice could be this physiological model people in the field were missing to investigate the mechanisms that lead to NASH.

And of course, we were very excited about it. But unfortunately, it turned out that the scientific community did not share our excitement and we were not able at the time to publish or receive any grant applications. One of the most common comments that we received back then was that the phenotype that we observed was "in the bestcase scenario relevant for mice, but surely not to humans..." 
But after this period, the increases in the incidence of obesity received more and more attention...Also the fact that in the recent decade even young children started to suffer from obesity and the metabolic risks associated with overweight increased the attention in our research.

But our biggest support actually didn't come from the scientific clinical community: surprisingly enough it came from Hollywood. The American documentary movie "Super Size Me", was directed in 2004 by Morgan Spurlock, an American independent filmmaker.

This movie follows Morgan during a one-month period in which he was only allowed to eat food from McDonalds. The movie demonstrates the drastic effect this type of diet has on Morgan's physical and psychological well-being, which included weight gain (11 kilos in one month), increased lipids levels in the blood and fat accumulation in his liver. In fact, during the film his doctors told him that if he did not quit, the damage to his liver would become irreversible...While the film was far from being a scientific experiment, it received widespread attention from the media and from that moment on, it became much easier for us to promote our hyperlipemic NASH mouse model. It probably also does not come as a surprise that I never take my children to McDonalds since then....

So what do we know about NASH? When we eat too much fat, some of the fat also goes to the liver and accumulates there. And, the more fat we eat, the more fat accumulates inside our livers. Accumulation of fat in the liver is actually a pretty common condition, which is present in about 15 percent of the general population and in 90 percent of the obese people. The fat in the liver is not necessarily harmful for the liver itself and it is even a reversible condition. But, similar to our observations in the hyperlipdemic mice, in about 50 percent of the morbidly obese individuals, in addition to fat accumulation there is also inflammation. This inflammatory response in the liver is considered to be a key event in the development of NASH since it can lead to a severe non-reversible damage to the liver. If left untreated, NASH can progress to permanent scaring of the liver and eventual liver failure. 
Since we still do not fully understand the mechanisms that are leading to NASH, we also do not have good diagnostic tools to follow the progression of the disease in a non -invasive way. The currently used markers lack the specificity and sensitivity to distinguish between simple accumulations of fat in the liver to NASH. The only way to get a clear diagnosis of NASH is to perform a liver biopsy, but this procedure is invasive, painful and can lead to rare but severe complications.

Another problem that is related to NASH is the lack of treatment. As we can't follow the progression of the disease in a non-invasive way and NASH is mainly asymptomatic, in many cases, by the time we get a clear diagnosis of NASH, the damage to the liver is already done and liver transplantation is the only solution. Currently NASH is the second reason for liver transplantation and is expected to be the first one by the end of 2019 .

Using our unique mouse model, we were aiming to explore the bridge between lipids and inflammation. Our specific question was to investigate the reason why some people have a lot of fat in their liver but do not develop inflammation while others have little amount of fat in their liver and yet develop severe inflammation and damage to the liver.

Before I will share with you what we discovered in the hyperlipidemic mice, I will first explain the process by which fat is taken up into the cells under normal conditions:When we are healthy, fat that is taken up by the receptors on the liver cells and first enter the lysosomes. Lysosomes are small cellular organelles that contains lysosomal enzymes that have the function of breaking these lipids. After the lipids have been broken, they can leave the lysosomes, via a transporter that is called NPC1, and either be stored in the cytoplasm of the cell or move back into the blood. However, when levels of lipids are high, as observed in obese people (and in our hyperlipidemic mice), the lipids circulate longer in the blood. 
As a consequence, during this time, a small fraction of the lipids gets oxidised. When these oxidised lipids are taken up by the cells and get into the lysosomes they can't move back to the cytoplasm as their nonoxidised counterparts do, and therefore they accumulate inside the lysosomes. Remarkably, we found that the accumulation of lipids inside the lysosomes was associated with the development of inflammation. The more lipids that were present inside the lysosomes, the more severe the inflammatory reaction that we observed.

To summarise our findings: When the lipids are located inside the cytoplasm we don't observe inflammation. However; when the same amount of lipids are located inside the lysosomes we observe inflammation and damage to the liver. So inflammation is not correlated with the amount of fat in the liver but rather with the intracellular localization of the fat. We concluded that it is all about the location: meaning that the accumulation of lipids and specifically oxidized lipids inside the lysosomes could be a possible trigger for the inflammatory response.

At this point of our research, the scientific community embraced our papers and our hyperlipdemic mice were finally recognized as an established model for NASH. We therefore felt ready to move into translational studies. And in collaboration with Dr Ger koek, our aim was to translate the molecular mechanisms that we found in these mice into novel ways to prevent NASH.

Here is what we put forward: If oxidised lipids are the trigger for liver inflammation, we should be able to prevent NASH by blocking the uptake of the oxidised lipids by liver cells. To investigate this hypothesis, we collaborated with Prof Christoph Binder from Vienna who had a very elegant way of increasing antibodies against oxidized lipids in the blood through a simple, non toxic vaccination. These antibodies bind specifically to the oxidized lipids and prevent their uptake by the receptors present on liver cells.

We performed an experiment by which one group of mice received the control injections and the other group received the immunization and 
therefore had high levels of antibodies against oxidised lipids. The immunization was done before the mice received the high fat diet. So, in practice, we first immunized the mice and only after we confirmed that the levels of antibodies against oxidised lipids were increased, we started with the feeding of the unhealthy high fat diet. If the mice did not undergo immunization we observed a clear difference between the group that received the low fat diet and the group that received the high fat diet. In the liver of the mice that received the unhealthy high fat diet many more inflammatory cells were present compared to the livers of the mice that received the low fat diet. This is indicated here by the red dots which represent inflammatory cells. However, if the mice received the immunization before they were given the high fat diet we could not tell anymore the difference between the mice that ate the healthy diet or the mice that received the unhealthy diet as the number of inflammatory cells was identical. As the amount of oxidised lipids in the blood is minor compared to the amount of nonoxidised lipids, these results were far better than our most optimistic expectations and clearly pointed towards the key role of oxidised lipids in NASH.

A very effective way to prevent NASH in early stages is to stop eating unhealthy diet and simply switch to a diet, that is low in fat, sugar and cholesterol. However, for most people it is easier said than done.

In fact, the majority of patients with NASH find it difficult to convert to low fat diet even after they received the diagnosis of NASH. Our aim was to develop in addition to the immunological intervention that I showed you, also dietary intervention that will block the harmful effects of the unhealthy diet. Together with prof Jogchum Plat we investigated the effect of plant stanols on inflammation. Plant stanols are dietary substances that are found naturally in plants and can prevent cholesterol from being absorbed into the bloodstream. The idea behind it was to reduce the levels of cholesterol in the blood and thereby to reduce the amount of cholesterol that will be oxidized and the development of inflammation. For this aim, we fed one group of mice unhealthy high fat diet and another group of mice received high fat diet that was mixed with plant stanols. 
After 3 weeks we investigated the livers. In line with our expectations, if the mice received low fat diet, they demonstrated a healthy liver. And, in mice that received high fat diet, we observed infiltration of inflammatory cells. But, remarkably, the liver of the mice that received the plant stanols looked exactly the same as the mice that received the low fat diet (Despite the fact the amount of fat and calories was much bigger). This approach seemed to be very useful and effective in preventing NASH and currently we are busy setting the clinic trail to test it on humans.

We have to keep in mind that NASH is mainly asymptomatic disease, which means that by the time it is discovered, most patients suffer from advance stages of $\mathrm{NASH}$, where it is already too late for prevention. Therefore, in addition to prevention there is also an urgent need for treatment. Our aim was to find a way by which we can redirect the oxidised lipids from the lysosomes into the cytoplasm.

The main problem was that back hen then lysosomal lipids has been observed to be highly resistant to removal. In collaboration with Prof Dieter Luetjohann, we finally discovered that the compound $27 \mathrm{HC}$, which is naturally found in our body, is able to improve the transition of cholesterol from the lysosomes to the cytoplasm. To test the ability of $27 \mathrm{HC}$ to be used as a treatment for NASH we fed the mice first with the unhealthy diet and only after they had already developed a significant accumulation of lipids in the lysosomes and displayed an advanced stage of NASH, we treated them with this compound.

We observed that indeed by treating the mice with 27HC, we were able to reduce the level of inflammation in the liver. These data are very promising, since it was the first indication that lysosomal cholesterol can be removed. We concluded that NASH could be treated even at the stage were the lysosomes are already filled with lipids when there is an advanced inflammatory response.

We next asked ourselves whether we can use the same mechanism to improve the diagnosis of NASH: The idea behind it was that under normal conditions, as seen in the left side of the slide, the lysosomes secret a certain amount of their lysosomal content into the blood. 
We observed that when the lysosomes accumulates oxidized lipids as seen at the left side of the slide, they become bigger, they get closer to the plasma membrane, and they move slower. Consequently the normal secretion of the lysosomal enzymes into the circulations is increased. We therefore expected that the amount of lysosoaml enzymes that is present in the blood of patients with NASH is higher compared to the amount of lysosomal enzymes that is present in the blood of healthy individuals and therefore that lysosomal enzymes can be used as markers for the development of NASH.

At this point we decided to cross the bridge between mouse research to humans reserch. In collaboration with Dr Ger koek, Prof Wim Burman, Prof bart Steals, Prof Valerio Nobili, Prof Steven Olde Damink, Prof Patrick Rensen, members of the CAVON project and many other national and international collaborators, we obtained access to patients cohorts, measured the presence of lysosomal enzymes in their blood and to compare it to the liver biopsies.

So how could we test whether lysosomal enzymes in the blood can be used an accurate biomarker for NASH? For a maximal accuracy a marker should be $100 \%$ sensitive: meaning not to miss any patient. It also has to be $100 \%$ specific: meaning not to include any healthy individual in the patients group.

I would like to share with you a study in which we investigated whether the lysosomal enzyme Cathepsin D could be used as a marker for NASH in a children cohort. These children are between the age of nine to eleven and they already had to go through the invasive procedure of liver biopsy. Using one of the most common currently used biomarkers, we had an accuracy of 59\%, which is of course not sufficient. Remarkably, by measuring the activity of the lysosomal enzyme catD in the blood we were able to increase our accuracy to 94\%. We already tested this marker in several other patient cohorts and obtained similar results. We also observed that this marker appears earlier in the blood compared to the current marker and therefore allows earlier diagnosis. 
We therefore concluded that the lysosomal enzyme CatD is an excellent early marker that can replace our need to perform a liver biopsy in the future. We are looking forward to apply it in clinics.

Since lipids and inflammation are also playing an import role in cancer and we know that oxidised lipids can also contribute to the progression of cancer, We recently decided to make the bridge from $\mathrm{NASH}$ to cancer and to investigate whether we can also improve cancer treatment by targeting the oxidised lipids. In collaboration with Dr Jan Theys we tested the effect of oxidised lipids on chemotherapy efficiency, by using the same approach as I showed you before: adding antibodies against oxidised lipids to cells that are treated with chemotherapy.

If we simply treat cancer cells with chemotherapy our aim is to eliminate these cells and indeed the amount of cancer cell survival is reduced. As many cancer patients have increased levels of oxidised lipids in their blood, we added oxidised lipids to the cells to mimic the physiological conditions. In line with our expectations, under these conditions, the amount of cancer cell survival (living cancer cells) was increased, indicating that chemotherapy may be less efficient when the level of oxidised lipids in the blood is increased. Remarkably, when we added the antibodies against oxidised lipids to the medium, the amount of cancer cells that survived the chemotherapy was reduced, indicating that these antibodies against oxidised lipids could potentially increase chemotherapy efficiency. By now, we already obtained similar results for this treatment in various cancer cells types and with several different classes of chemotherapy. As increased levels of oxides lipids are naturally present in the blood of many cancer patients, we are very optimistic about this new direction in research and we are looking forward to test it in our hyperlipidemic mouse models. 
Working on common diseases like NASH and cancer has the advantage when it comes to relevance has it is a major problem for society so research funds are willing to sponsor it and high relevance also helps when it comes to publications. However, many rare diseases are left with no treatment or diagnosis, as it is less of an interest to the general society. Since the accumulation of lipids in lysosomes as observed in NASH is similar to a phenotype of in a rare and fatal disorder called Niemann-Pick C1 disease, or shortly NPC1, we decided to make the transition from common to rare diseases and to investigate NPC1.

So what is NPC1 disease? NPC1 is a transporter that is responsible for the transport of the fat from the lysosomes to the cytoplasm. A mutation in the gene encoding for this transporter disrupts intracellular fat flow and leads to the accumulation of fat products in the lysosomes. In that sense the phenotype is similar to our observations in NASH. But, unlike NASH, the accumulation of lipids in lysosomes of NPC1 patients is much more severe. Another difference between NASH and NPC1 is that in contrast to NASH, in cells of NPC1 patients, it is mainly non-oxidised lipids that accumulate in lysosomes. In addition to severe liver disease, inflammation and respiratory failure, children carrying a mutation in NPC1 suffer from a wide spectrum of neurological symptoms ranging from developmental delay, dementia and mental disorders. These children can gradually become disabled, making oral feeding impossible and eventually leading to death. Like many other rare diseases, an effective treatment is not available. Our aim was to investigate whether the interventions that we performed in relation to NASH will also be beneficial in the context of NPC1 disease.

For this purpose we obtained the NPC1 mice. Similar to humans, mice that carry a mutation in the NPC1 transporter suffer from developmental disorders increase liver weight due the accumulation of lipids in lysosomes of liver cells and decline motor function. If left untreated these mice will die in about the age of 8 weeks. 
We first started with the immunization treatment. We gave a group of mice that suffer from NPC1 diseases immunization to boost the production of antibodies against oxidised lipids (the same immunization that I showed you before) and the other group received control injections. After we ensured that there are high levels of antibodies against oxidised lipids in the immunized mice, we investigated the livers.

Strikingly, We observed that the mice that received the immunization had significantly less infiltration of inflammatory cells in the brain compared to the control mice. We also observed similar results in the livers of these mice: along with a reduction in the storage of lipids in the liver there was a reduced inflammtion. These significant improvements in the metabolic function of the mice were also reflected by improved motor function Mice that received the immunization were stronger, they were more in balance and they had better orientation.

Another intervention that we are currently testing in relation to NPC1together with Prof Joghum Plat and Prof Dieter Luetjohann is the stanol diet that I showed you before which aims at reducing the amount of dietary cholesterol that is taken up by our intestine.

While these studies are still on going, I can already share with you that the mice that received the plant stanols from an early age demonstrated reduced NPC1 related pathology compared to mice that didn't receive the stanols. Compared to control mice, mice with NPC1 disease, demonstrated an increased liver weight due to a massive accumulation of lipids in the lysosomes of liver cells. Upon feeding stanol diet, we observed reduce storage of fat in the liver. In line, the natural development of these mice after birth was dramatically improved in the mice that received the stanol diet. Altogether, the results of our intervention studies in NPC1 mice were far beyond our expectations as most lipids inside lysosomes are not oxidised. These data provide the first demonstration for the important role of oxidised lipids in NPC1 and provide an effective non-toxic treatments for NPC1 patients, which can delay disease progression significantly. 
Last summer, I attended a NPC1 conference which was organized by friends and family of NPC1 patients and it was here that I met the parents of Abby and Bella. Unfortunately, both Abby and Bella were diagnosed with the NPC1 disease a few months before the conference. I would like to share with you part of an e-mail that I received from their father after the conference: "When your children have a rare disease, you spend much of your time feeling completely alone. To be in a room with so many people working to help our daughters was incredibly overwhelming and filled our hearts with gratitude."

The thought of these two beautiful girls and other patients fills me with enormous motivation to continue in the field of NPC1, despite of the difficulties associated with investigating a rare disease.

And in that context, I am very happy that we recently in collaboration with Prof. David Cassiman we received the ethical approval to start a clinical trial in patients I am not only looking very much looking forward to start the trial, and to see the first results. For Abby. For Bella and for all the other patients. This tight link between lipids and inflammation can also be applied beyond diseases in which we are already involved right now. Among others, these diseases include inflammatory bowel disease, COPD and Alzheimer's disease.

We have already started studies in the context of some of these dieases and I am very excited about moving further into new directions together with our national and international collaborators.

My work at the university is not limited to research alone. Also education is a very important part of my job. I truly love being surrounded with young students from all over the world through my roles as coordinator, mentor, tutor, coach and supervisor.

I am therefore happy to contribute to the 'international orientation' of the university via my involvement both in the internationalization platform and in the internationally-oriented biomedical master programme. My goal, together with Dr Wilfred Germeraad, Dr Ramon Langen and Dr Jan Theys is to spread our experience in this programme to other universities across the world. Together with my colleagues, I intent to create a supportive environment for foreign 
students in Maastricht where differences are celebrated and valued for the strength they bring to society. But much more than helping others, being able to contribute to the integration of foreigners in Maastricht, makes me feel at home.

Unfortunately, I miss today the one person to whom I would like to thank the most; the late Prof Marten Hofker. It is thanks to Marten that I have the privilege to stand here today in front of you. Marten was the first person I met when I just arrived from Tel-Aviv and the best mentor anyone can ever imagine. There are no words to describe the impact he had on both my scientific career and my personal life.

Marten not only taught me everything I know about science, but he also taught me how to believe in myself and how to fight even when chances of success are very low. With his optimistic approach and unmatched passion for science, he was, and still is, an inspiration to me and many others. It means a lot to me that his beloved partner Prof Cisca Wijmenga honoured me with her presence today, makes me feel like part of him is here with us.

Marten always believed that science is a team sport that you enjoy doing together without thinking of your own interests and he was of course very right. I don't think it is possible for me to name all the people that I am grateful for them and I am also afraid of forgetting someone. Not to mention that I have problems to pronounce all these last names accurately. But still there are some people that I really would like to mention: First, the committee members that supported this appointment, Prof. Albert Scherpbier, Prof. Nanne de Vries, Prof Annemie Schols who also provided me all these years with extensive support as the director of NUTRIM and Prof Jan Glatz who supports me daily as the head of our department.

I am very grateful to all of you for your trust in me, for your advice, for your on going support. Next, I would like to thank all my international and national collaborators, some of them I have already mentioned during my presentation but there are too many to name them all. 
I also would like to thank the people that share with me my educational and management duties. It is thanks to you that these duties are mostly so much fun. Most importantly, I would like to thank all the young and talented previous and current members of my group who actually worked very hard to create all the data that I have showed you today and in fact it is them that actually deserve much of the credit. And of course I would like to thank each and every one of you that came here today especially for me.

I have now come to another emotional part. This day would have been meaningless to me if it wasn't for my amazing parents Tikva and Avner Shiri who are sitting here in the audience without understanding a word in English. My parents struggled all the years to give me what they couldn't have for themselves. I can't even begin to describe how it makes me feel that they are here today, together with my two sisters and my brother. I am so much more than grateful for the rare opportunity that I have to spend two more precious evenings with all of them here in the Netherlands.

My very very dear husband Erez. Thank you for being the rock in my life and for bringing the excitement and adventures to our family with your endless amount of energy. Without you my life would have been so much more boring and much less fun, for sure. I feel fortunate that I can share with you the joy of raising our most beautiful children. Beautiful in every possible way....Shahar, Ofek, Marom, Agam; you are my biggest achievements in life, you are my source of happiness, my daily light, my everything. With all of us together it is home. And in this case location doesn't matter...

Changing locations from Tel Aviv to Maastricht was not easy. There is always part of me that is missing. But today, when I see all of you together, when the two main locations in my life are mixed, I feel that I stand on a strong bridge. I feel complete.

Ik heb gezegt 